\title{
Preliminary structural analysis of a conceptual design for a small-scale erectable lunar habitat
}

\author{
Jian Fan ${ }^{\mathrm{a}}$, Chuan-Chang Yang ${ }^{\mathrm{b}}$, Elton J. Chen ${ }^{\mathrm{a}, \mathrm{b}, *}$, Han-Bin Luo ${ }^{\mathrm{a}, \mathrm{b}}$ \\ ${ }^{a}$ School of Civil Engineering \& Mechanics, Huazhong University of Science \& Technology, Wuhan 430074, China P.R. \\ ${ }^{b}$ Center for Virtual, Safe and Automated Construction of Hubei Province, Wuhan 430074, China P.R.
}

\begin{abstract}
Manned lunar exploration, again, becomes a research focus in recent years, and a number of the leading countries and regions, have announced their own programs. Beyond moon landing, scientists and engineers have started paying more attention on construction techniques for lunar habitation base. This paper introduces a new conceptual structural design of an erectable lunar habitat, using prefabricated building blocks made from the in-situ lunar regolith. The flank wall and foundation of the lunar habitat are fabricated by cubic blocks, among which joggle joint is adopted. Moreover, the roof is erected by arch segments with joggle joint as well and a 2m-thick lunar regolith layer is placed on top to shield the whole structure against the hostile environment. As to the environmental conditions on the Moon (1/6 of the earth gravity, temperature variation of approximate $300 \mathrm{~K}$ within a lunar day and frequent moonquake), those loads, which would be regarded as irregular on earth, are actually regular for our lunar habitat structure. In order to investigate the behavior of the structure under such extreme loading, a 2D numerical model is established using the finite element software, ABAQUS. In this preliminary study, responses of the habitat structure under static loads of self-weight, overburden pressure, internal air pressure and temperature variation, are simulated. The simulation results give us some requirements on the structural design of this erectable lunar habitat. Several concluding remarks are drawn for both the building block system and the In-Situ Resource Utilization (ISRU) technique of lunar regolith.
\end{abstract}

(C) 2018 The Authors. Published by Diamond Congress Ltd., Budapest University of Technology and Economics Peer-review under responsibility of the scientific committee of the Creative Construction Conference 2018.

Keywords: erectable lunar habitat; conceptual design; finite element; extreme loading; structural analysis;

\section{Background}

Adjacent to our Earth, Moon is the nearest celestial object, which is also one of the potential energy storehouse for human beings in the future (OuYang, 2005, Badescu, 2012) ${ }^{[1,2]}$. Helium-3 is a new fuel for nuclear fusion, the reserves of which could serve human beings for more than ten thousand years (ESA, 2018) ${ }^{[3]}$. In this case, manned lunar exploration, again, becomes a research focus in recent years, and the leading countries and regions, such as the United States, Russia, the European Union and China, have all announced their own Moon-landing programs (Wikipedia, 2018) $^{[4]}$, a series of Mega-Projects (Brookes 2014) ${ }^{[5]}$. In order to return to Moon for further exploration, habitats for the astronauts are required for long-duration missions on lunar surface. Hence, it is necessary to develop techniques of lunar base construction. For four decades, NASA has been attempting to create a lunar habitat that can support life for an extended period of time (O'Donnell and Malla, 2017) ${ }^{[6]}$.

From 1970s, a number of researchers put their efforts on lunar base study and several structural patterns were proposed. The major patterns are, (1) inflatable structure, (2) rigid structure and (3) mixed structure. For inflatable structure, Nowak et al. (1994) $)^{[7]}$ designed a modular inflatable structure consisting of thin membranes of composite material integrated with supporting columns and arches. For rigid structure, Lin et al. (1989) ${ }^{[8]}$ proposed a 
prefabricated pre-stressed concrete structure with diameter of 120 feet and height of 70 feet. For mixed structure, Aulesa (2000) ${ }^{[9]}$ theoretically proposed a mixed inflatable (transported)-rigid structure (cast basalt, produced in situ), a hemispherical shell structure (dome) covered with a layer of regolith to shelter cosmic radiation.

Due to high transportation costs, ISRU is mandatory in lunar habitat construction (OuYang, 2005, Badescu, $2012)^{[1,2]}$. Lunar regolith, the most abundant and available lunar resource, is commonly suggested as a shielding material during the first stages of lunar colonization (Aulesa, 2000) ${ }^{[9]}$. This paper proposes a new structural pattern of lunar base, a small-scale erectable lunar habitat, which is fabricated with erectable lunar regolith blocks and shielded with compacted lunar regolith layer. Moreover, preliminary structural analysis is carried out, including structural responses subject to common static loads as well as the thermal field, which indicates the functional behavior of the lunar structure against the extremely variable temperature. Finally, several material and structural requirements for the lunar regolith blocks are concluded based on the preliminary analysis, and ongoing research work is introduced.

\section{Conceptual structural design}

The Moon, with a number of similarities, is indeed an alien environment, which is significantly different from our Earth, e.g. as the landform of Moon shown in Fig.1. However, these similarities and differences might also provide us unique opportunities for using the lunar environment and its resources in future space exploration (Aldrin and Eckart, 2006) ${ }^{[10]}$.

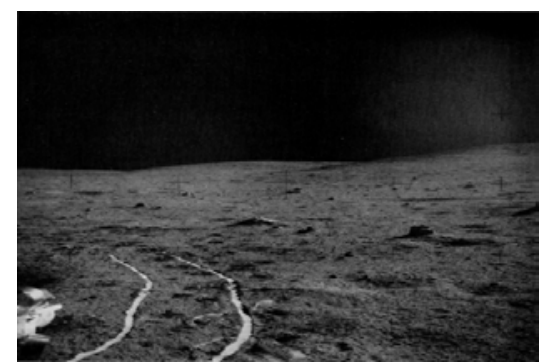

Fig. 1. The landform of lunar surface (Aldrin and Eckart, 2006) ${ }^{[10]}$

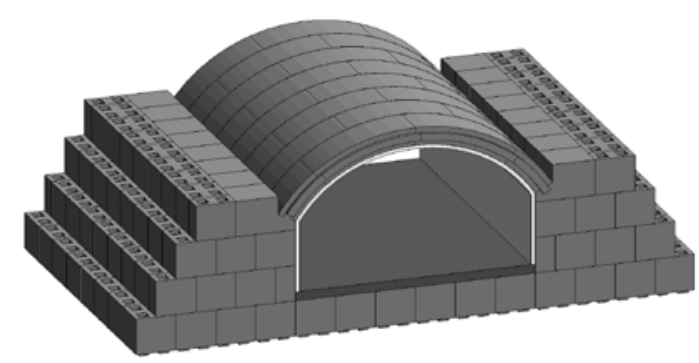

Fig.2. 3D view of the conceptual lunar habitat

This study proposes a new conceptual design of the lunar base, a small-scale erectable lunar habitat. For this conceptual design, a hemispherical arch structure is proposed. It is a prefabricated structure, as shown in Fig.2. The structure composes of a series of standard erectable cubic blocks and arch roof segments, which are made from the in-situ lunar regolith (sintered by microwave or autoclaved). Four types of blocks are designed, i.e. standard block, arch foot block A/B, full arch segment and half arch segment, as shown in Fig.3a, b, c and d, respectively. Standard blocks are erected for the flank wall and the foundation. The width of the flank wall are both $4 \mathrm{~m}$, while the internal width of the habitat is about $6 \mathrm{~m}$. The arch foot blocks are used to connect the flank wall and the arch roof and also transfer the roof load to the flank wall and foundation. The arch roof consists of three full segments (or two full segments plus two half segments). Total height of the structure could be more than $5.5 \mathrm{~m}$. The cross-sectional area of the internal space is about $20 \mathrm{~m}^{2}$ and the length at the longitudinal direction is flexible. In addition, a thick lunar regolith layer is placed on top of the lunar habitat to shield the whole structure against the hostile environment.

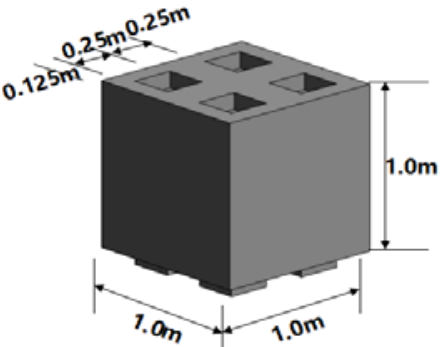

(a)

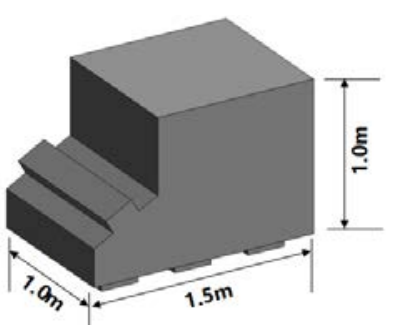

(b)

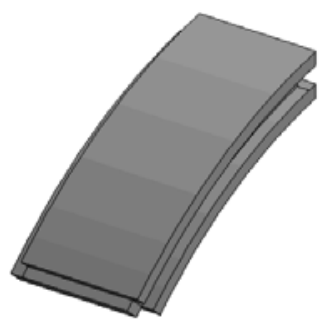

(c)

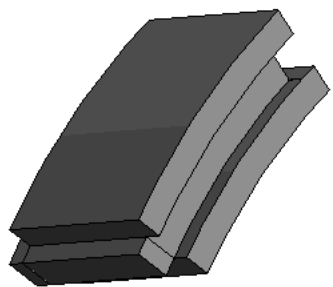

(d)

Fig. 3. (a) Standard block; (b) Arch foot block A; (c) Arch roof segment (full); (d) Arch roof segment (half) 
As shown in Fig.3, the size of standard block is suggested to follow certain standard modulus, and here we propose the modulus size as $1 \mathrm{~m}$. Moreover, the joggle joint between each two standard blocks are Lego style, with four cogging joints. Arch foot blocks (A/B) provide support to the arch roof. Block A is the convex block while B is concave. It is designed to fix the base of the arch roof. The arch roof segments are precast also with convex and concave edges, the shape and connection pattern of which are similar to the lining segments in shield tunneling on Earth. Due to the pattern of stagger-jointed assembling of the arch roof segments, a type of half arch roof segments is used in every other arch. With this design, the erectable structure could be constructed in the longitudinal direction as long as required, and more complex lunar base could also be considered by connecting a number of modularized structural units.

To resist extreme temperature on the Moon and the cosmic radiation, a compacted lunar regolith layer is designed to cover the whole structure. The thickness of the layer is determined based on literature investigation of previous researcher's work. According to Duke's (2006) ${ }^{[11]}$ study, a 2m-thick regolith layer could shelter the lunar base from solar flare radiation, while Vaniman et al. (1991) ${ }^{[12]}$ investigated heat flow data from Apollo Moon-landing Project and concluded that an insulating blanket of only about $30 \mathrm{~cm}$ of regolith is sufficient to dampen out the $\sim 280^{\circ} \mathrm{K}$ lunar surface temperature fluctuation to $\pm 3^{\circ} \mathrm{K}$ variation. Jolly et al. $(1994)^{[13]}$ suggested the thickness should be between $1 \mathrm{~m}$ to $4 \mathrm{~m}$ based on the specific requirements of the lunar environment and the construction factors. Therefore, in the following study, we assume the thickness of the lunar regolith layer is $2.0 \mathrm{~m}$.

\section{Finite element model}

A 2D finite element model is established in the finite element software, ABAQUS, for static analysis for the proposed lunar habitat, as shown in Fig.4. PE4 element (4-node bilinear plain strain quadrilateral) is used to simulate the cross section of the structure. Totally, 3678 meshes are generated. Since the lunar regolith block is closed to concrete on Earth, several basic properties are assumed as follows, the elastic modulus: $3.0^{*} 10^{4} \mathrm{MPa}$, poison ratio: 0.3 , density: $2500 \mathrm{~kg} / \mathrm{m}^{3}$. The considered static loads include the pressure acting on the structure caused by the compacted lunar regolith layer, self-weight of the structure and internal air pressure that maintains when the habitat is in operation.

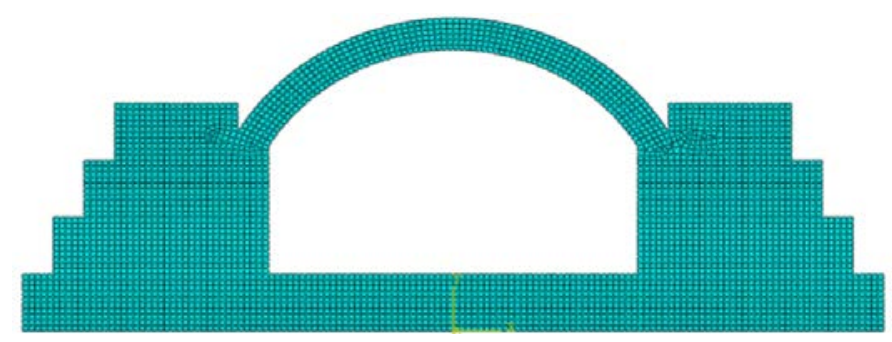

Fig.4. 2D finite element model of the proposed lunar structure

\section{Structural behavior under static loads}

As to the environmental conditions on the Moon, especially in terms of lunar base construction, it is significantly different from that on Earth. For instance, the gravitational acceleration is only 1/6 of that on Earth; temperature approximately varies $300^{\circ} \mathrm{K}$ within a lunar day; and moonquake frequently occurs although most of the magnitudes are below 3.0 (Luke et al. 2006) ${ }^{[11]}$. These loads, which are usually regarded as irregular loads in our construction industry on Earth, are actually regular for our lunar habitat structure.

\subsection{Overburden pressure induced by the lunar regolith layer}

Williams and Jadwick (1980) ${ }^{[14]}$ pointed out that the volume density of lunar regolith varies from $1500 \mathrm{~kg} / \mathrm{m}^{3}$ to $1700 \mathrm{~kg} / \mathrm{m}^{3}$ at the Moon surface. As to the compacted overlaid regolith layer, the density might depend on the grain size of the lunar regolith and the construction method. Since the layer is to be compacted during the construction, the volume density of the overlaid layer in this study is set as $1740 \mathrm{~kg} / \mathrm{m}^{3}$, which is equivalent to dense sand on Earth and will generate a uniform downward pressure of $5.67 \mathrm{kPa}$ in the vertical direction (density*thickness*Moon gravitational acceleration). 


\subsection{Self-weight of the structure}

On the other hand, the density of the lunar regolith blocks is set as $2500 \mathrm{~kg} / \mathrm{m}^{3}$. Moon gravitational acceleration is one sixth of that on Earth, i.e. $1.63 \mathrm{~m} / \mathrm{s}^{2}$, thus the self-weight body force is $4.08 \mathrm{kN} / \mathrm{m}^{3}$.

\subsection{Internal air pressure}

The lunar habitat is a closed environment with life support system. Therefore, certain internal air pressure is maintained during the base operation. There is no air from the outside to balance the internal air pressure, thus the internal pressure actually becomes an unfavorable load to the proposed structure. Commonly speaking, the best internal pressure is the Earth atmospherical pressure. However, due to safety reasons, it is required that the pressure difference between EVA (extravehicular activity) suit and the internal atmosphere should be as small as possible. Cross et al. (2009) ${ }^{[15]}$ compared the cabin pressure of Apollo and Orien driving environment and mentioned that the internal pressure of the lunar habitat that maintains within the range of $34.5 \mathrm{kPa}$ to $101.4 \mathrm{kPa}$ could provide astronauts with comfortable living environment. Therefore, in this study, the internal pressure of $69 \mathrm{kPa}$ is used.

\subsection{Model computation}

In current study, the preceding three static loads are considered in the model calculation. Moreover, two different working conditions, i.e. 1) construction stage and 2) operation stage, are also separately considered. For the construction stage, the loads includes only the structural self-weight and the overburden pressure induced by the lunar regolith layer, and there is no internal air pressure; for the operation stage, all the three loads apply.

Loading conditions in the model are shown in Fig.5, and model computation shows the following results, 1) principal tensile stress contours; and 2) principal compressive stress contours, as shown in Fig.6 and 7, respectively.
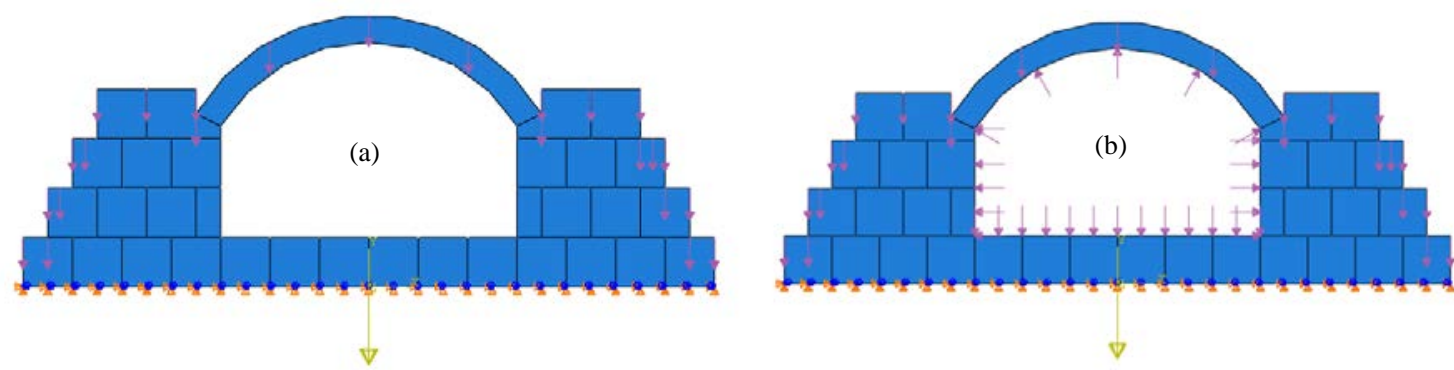

Fig.5. Loading conditions for (a) construction stage and (b) operation stage

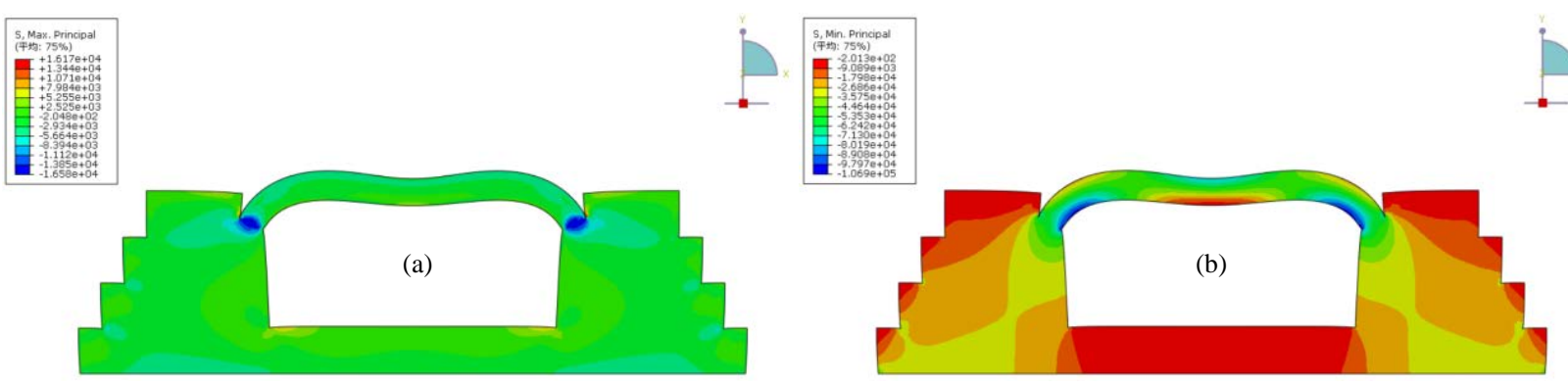

Fig.6. (a) Principal tensile stress and (b) principal compressive stress in construction stage

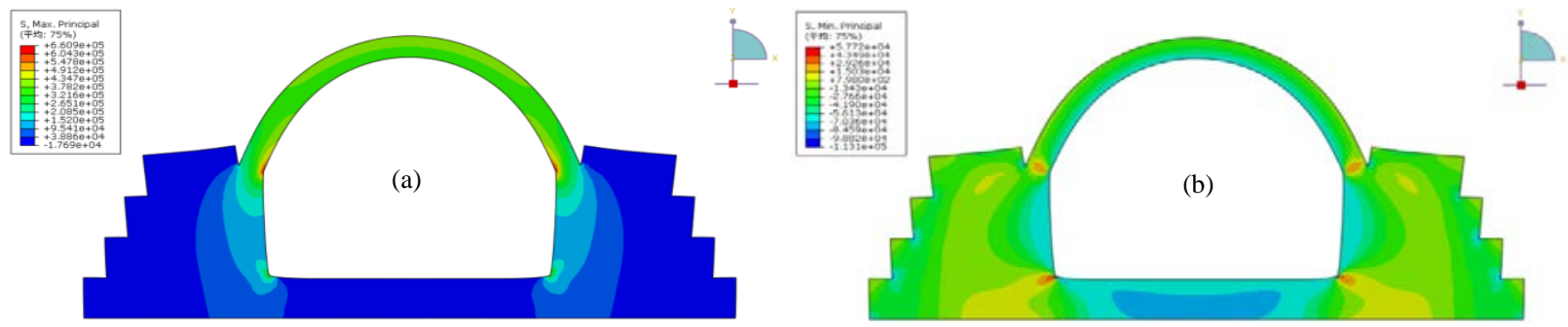

Fig.7. (a) Principal tensile stress and (b) principal compressive stress in operation stage 
From the results of model computation as shown in Fig.6 and 7, in construction stage, the maximum principal tensile stress is about $0.02 \mathrm{MPa}$ and the maximum principal compressive stress is $0.11 \mathrm{MPa}$; in operation stage, the maximum principal tensile stress is about $0.66 \mathrm{MPa}$ and the maximum principal compressive stress is $0.11 \mathrm{MPa}$.

Considering the proposed lunar habitat is a prefabricated structure, the principal tensile stress governs the structural safety. In this case, the maximum principal tensile stress in construction stage is only $0.02 \mathrm{MPa}$, so the structure is relatively safe. However, the structural maximum principal tensile stress in operation stage is up to $0.66 \mathrm{MPa}$, which locates at the connection part between arch roof segment and the arch foot. Prefabricated structure could not bear the tensile force as large as this level, thus we suggest that the internal air pressure should be undertaken by an internal membrane. Despite of this suggestion, we also recommend adding some special structural design to improve tensile strength of the connection.

\section{Thermal analysis}

A lunar day is equivalent to 28 Earth days with 14 days of sunlight and 14 days of darkness. At the equatorial latitude, the temperature varies from $374^{\circ} \mathrm{K}$ during the lunar noon to about $120^{\circ} \mathrm{K}$ at lunar night. The temperature variation decreases as the latitudes increase to the Polar Regions, where it varies from about 160 to $120^{\circ} \mathrm{K}$ (Mottaghi and Benaroya, 2015) ${ }^{[16]}$.

We assume that the lunar base sits at the lunar South Pole, temperature data of one lunar day at the South Pole is needed for thermal analysis. It is assumed that the temperature drops quickly after the sunset while maintains constant during the night. According to Mottaghi and Benaroya (2015) ${ }^{[16]}$, the temperature variation within a lunar day can be calculated by the following equation,

$$
\mathrm{T}_{\mathrm{m}}= \begin{cases}161.607\left[\sin (11.4786 d+9.6495)^{1 / 6}\right] & \text { for } 0<d<14 ; \\ 120 & \text { for } 14<d<28\end{cases}
$$

The variation curve of the temperature is plotted in Fig.8. In the finite element simulation, the thermal analysis of this study considers two extreme conditions, i.e. thermal analysis for the lunar midnight and that for noontime.

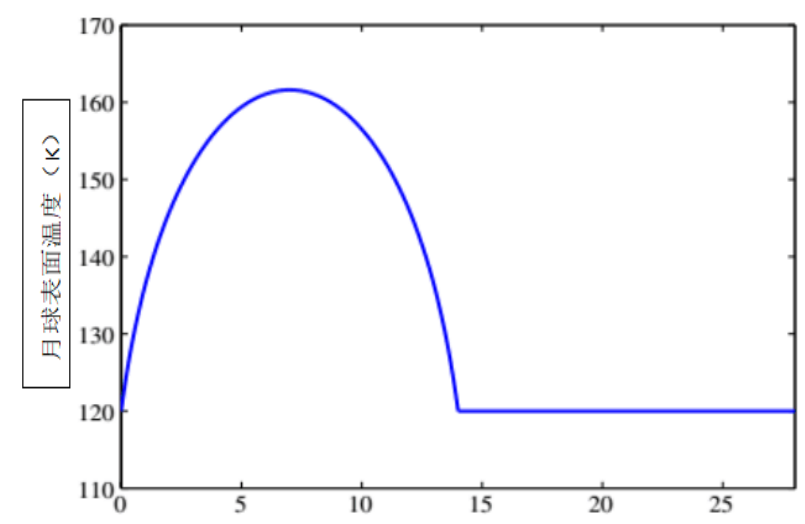

Fig.8. Temperature distribution within a day at the South Pole of the Moon (Mottaghi and Benaroya, 2015) ${ }^{[16]}$

\subsection{Boundary conditions}

From Fig.8, the temperature of lunar surface is $120^{\circ} \mathrm{K}$. Attributable to the absence of sunlight in the lunar night, the temperature uniformly distributes on the surface of the lunar base structure, which could set as $93^{\circ} \mathrm{K}$, the same as the temperature of lunar regolith (Hemingway, et al., 1973) ${ }^{[17]}$. The boundaries at left, right and bottom are set as heat-insulated boundaries for all working conditions. For lunar noontime, the temperature of lunar surface is set as $161.6^{\circ} \mathrm{K}$. Accounting for the sunlight effect, the side exposed under the sun could reach the temperature of $343^{\circ} \mathrm{K}$, while the other side is only $105.1^{\circ} \mathrm{K}$. Both conditions, the internal temperature maintains constant as $296.2^{\circ} \mathrm{K}\left(23^{\circ} \mathrm{C}\right)$. The thermal boundary conditions are shown in Fig.9 (a) and (b). 

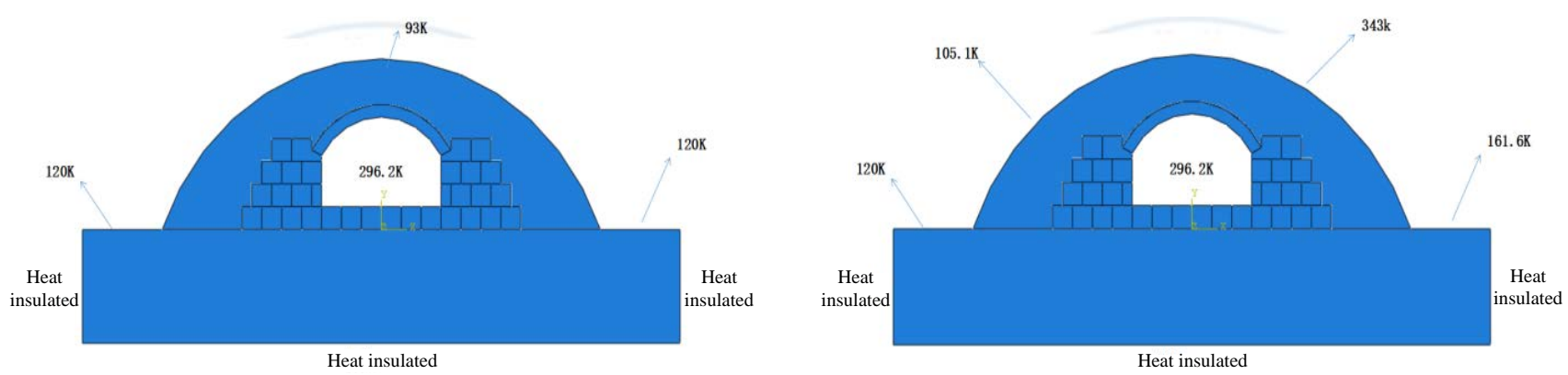

Fig.9. Thermal boundary conditions of the lunar base: (a) midnight; (b) noontime

\subsection{Thermodynamic parameters of material}

Before thermal analysis, thermodynamic parameters should be determined. The lunar base structure composes of regolith shielding, foundation and the structure. Regolith shielding is a compacted layer of weathered soil from the lunar surface. Heminway et al. (1973) ${ }^{[17]}$ tested samples from Apollo 14, 15 and 16 and found the specific heat capacity and heat conductivity of the lunar regolith with the temperature variation between $90^{\circ} \mathrm{K}$ and $350^{\circ} \mathrm{K}$ (see Table 1). Those values in Table 1 are adopted in this study.

Table 1. Thermal parameters of the regolith shielding under different temperatures (Hemingway, et al., 1973)

\begin{tabular}{ccc}
\hline $\begin{array}{c}\text { Temperature } \\
\left({ }^{\circ} \mathrm{K}\right)\end{array}$ & $\begin{array}{c}\text { Specific heat capacity } \\
\left(\mathrm{J} / \mathrm{kg}^{\circ} \mathrm{K}\right)\end{array}$ & $\begin{array}{c}\text { Heat conductivity } \\
\left(\mathrm{W} / \mathrm{m}^{\circ} \mathrm{K}\right)\end{array}$ \\
\hline 100 & 275.7 & 0.0007 \\
150 & 433.9 & 0.0008 \\
250 & 672.4 & 0.0011 \\
300 & 758.1 & 0.0014 \\
350 & 848.9 & 0.0017 \\
\hline
\end{tabular}

For thermodynamic parameters of lunar ground, based on the data analysis of four groups of Apollo sample, Langseth et al. (1976) ${ }^{[18]}$ estimated the heat conductivity of lunar ground is about $0.9-1.3 \times 10^{-5} \mathrm{~W} / \mathrm{cm} \cdot{ }^{\circ} \mathrm{K}$ and the specific heat capacity is $670 \mathrm{~J} / \mathrm{kg}^{\circ} \mathrm{K}$.

As proposed in foregoing section, the lunar base structure is fabricated by lunar regolith blocks. We assume the thermodynamic parameters are similar to basalt on Earth, thus, the specific heat capacity and heat conductivity of $885 \mathrm{~J} /\left(\mathrm{kg}^{\circ} \mathrm{K}\right)$ and $1.65 \mathrm{~W} / \mathrm{m}^{\circ} \mathrm{K}$ are assumed, respectively.

\subsection{Analysis of temperature field}

With the determination of thermal boundary conditions and the material thermodynamic parameters, numerical model computation gives us the temperature field and heat flow plots in this preliminary study, as shown in Fig.10.

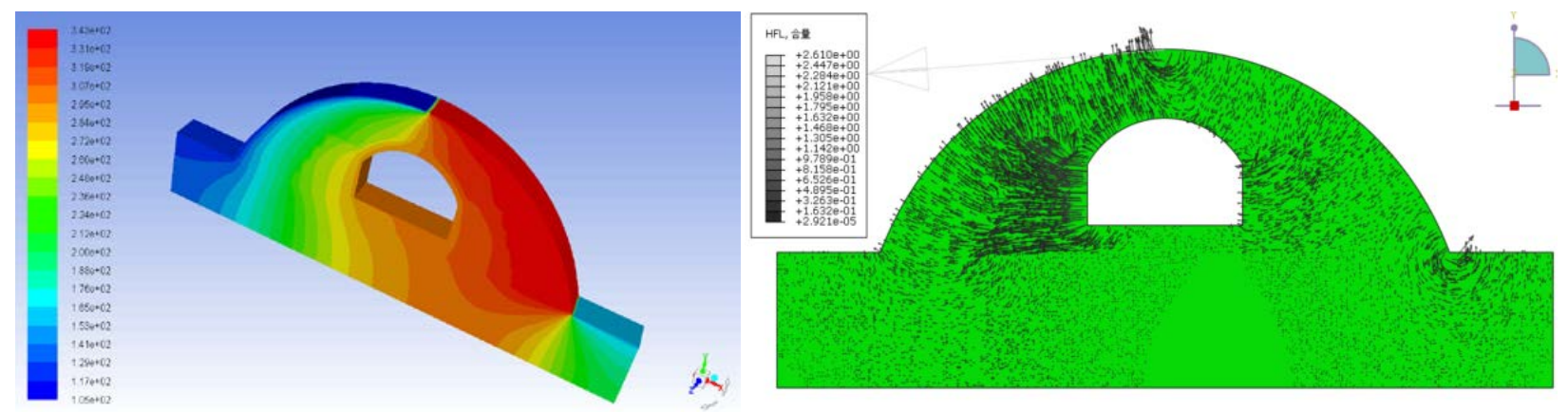

(a) Moon noontime 


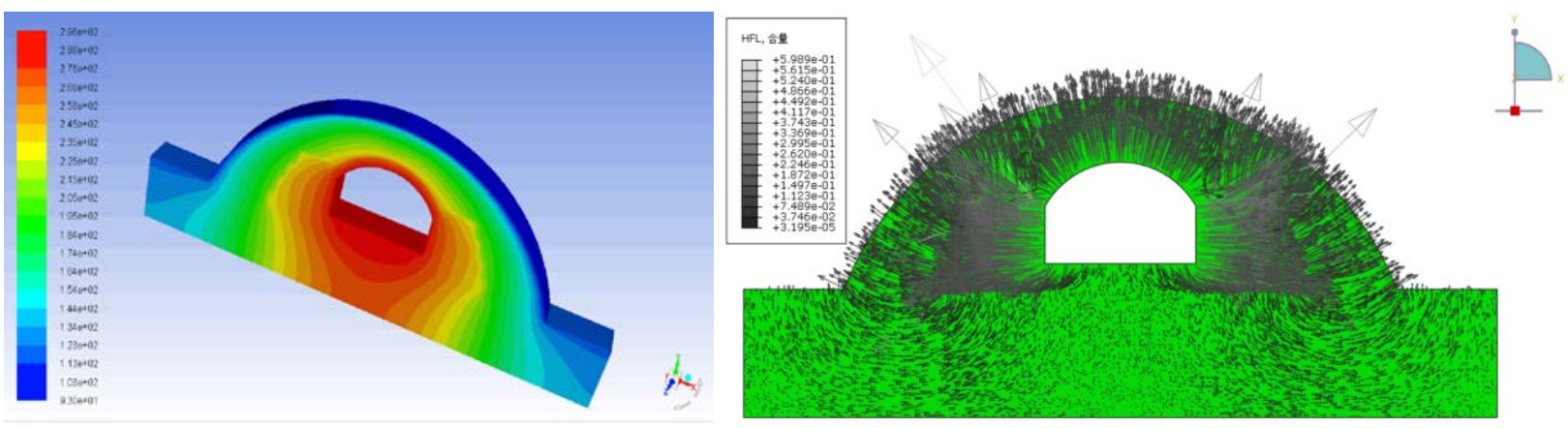

(b) Lunar midnight

Fig.10. Temperature field distribution and heat flow under two extreme conditions

Fig.10a indicates that, at lunar midnight, the difference between external and internal temperatures is relatively large, and the heat loss for unit length (one meter) of the proposed structure is approximately $22.3 \mathrm{~W}$. On the other hand, based on the calculation of the heat flow plots (Fig.10b), the heat loss at noontime for the same length of the structure is about 7.3W, much lower than that of midnight. The heat loss under both these two extreme conditions are still within a low range. These findings from the numerical simulation indicates that the proposed composite lunar habitat structure is relatively competent in heat insulation.

Other effects of the temperature field are investigated in progress, e.g. the extra loads induced by extremely large temperature variation within a lunar day.

\section{Conclusion and discussion}

To sum up, the following concluding remarks are drawn from this study.

(1) A new conceptual structural design of an erectable lunar habitat is proposed. According to the design, the main structure is fabricated in place by using erectable lunar regolith blocks as building material. In addition, a compacted lunar regolith layer with thickness of $2.0 \mathrm{~m}$ is placed on top to shield the whole structure against the hostile lunar environment.

(2) Based on the principle of structural design, the major loads the lunar habitat structure may encounter on Moon should be considered as regular loads, although they are normally regarded as irregular loads if it was on Earth.

(3) Considering three static loads, 2D numerical model has simulated the structural responses. The results suggests that, the proposed lunar habitat structure is relatively safe on compressive strength, but the tensile strength needs to be enhanced, especially the parts of the arch foot and the foundation fabricated by cubic blocks. A strong internal membrane is suggested to bear most of the tensile stress induced by the internal atmosphere.

(4) Temperature variation is also an unfavorable environmental condition. With some assumptions, numerical simulation shows the composite structure (structure plus shielding layer) is relatively competent with respect to heat insulation.

These are the four major conclusions in the preliminary analysis while the entire study is still moving on. Several groups are working in parallel for different aspects, including different structural patterns, innovative construction materials, construction equipment and techniques. In terms of structural part, thermal load and dynamic moonquake load are to be considered in the subsequent numerical modeling. On the other hand, structural testing for the model lunar regolith blocks, theoretical analysis for different structural patterns and physical modeling of the structure are planned.

\section{Acknowledgements}

The research is supported by the "Double-First Class Program" (World-class universities and World-class disciplines) and the Fundamental Research Fund for the Central Universities (Grant No. 2018KFYYXJJ005). 


\section{References}

[1] Z.Y. OuYang, Introduction to Lunar science, China Aerospace Industry Press, Beijing, 2005.

[2] V. Badescu, Moon: Prospective energy and material resources, Springer, Berlin, 2012.

[3] ESA, Helium-3: Mining on the Lunar surface, webpage, 2018.

[4] Wikipedia, Moon landing-Proposed future mission, 2018.

[5] N.J. Brookes, Mankind and mega-project, Frontiers of Engineering Management, 1(3), 2014, pp. 241-245.

[6] F.A. O'Donnell and R.B. Malla, Lunar Environtmental and Construction Challenges and a Proposed Semi-Circular Frame Membrane Habitat. AIAA SciTech Forum, 55th AIAA Aerospace Sciences Meeting, American Institute of Aeronautics and Astronautics, Grapevine, Texas, 2017, pp. 1-13.

[7] P.S. Nowak, W.Z. Sadeh and J. Janakus, Feasibility study of inflatable structures for a lunar base, Journal of Spacecraft and Rockets, 31(3), 1994, pp. 453-457.

[8] T.D. Lin, J. Senseny, L.D. Arp and C, Lindbergh, Concrete Lunar Base Investigation, Journal of Aerospace Engineering, 2(1), 1989, pp. 1019.

[9] V. Aulesa, Architecture of Lunar Habitats, Exploration and Utilisation of the Moon. Proceedings of the Fourth International Conference on Exploration and Utilisation of the Moon: ICEUM 4, B. H. Foing, and M. Perry, eds., European Space Agency, Noordwijk, The Netherlands, 2000.

[10] B. Aldrin and P. Eckart, The lunar base handbook : an introduction to lunar base design, development, and operations, McGraw-Hill, New York, 2006.

[11] M.B. Duke, The Lunar Environment, The lunar base handbook : an introduction to lunar base design, development, and operations, B. Aldrin, and P. Eckart, eds., McGraw-Hill, New York, 2006.

[12] D. Vaniman, R. Reedy, G. Heiken, G. Olhoeft, and W. Mendell, The lunar environment, Lunar Sourcebook, G. H. Heiken, D. T. Vaniman, and B. M. French, eds., C ambridge University Press, Cambridge, 1991, pp. 27-60.

[13] S.D. Jolly, J. Happel and S. Sture, Design and construction of shielded lunar outpost, Journal of Aerospace Engineering, 7(7), 1994, pp. 417434.

[14] R.J. Williams and J.J. Jadwick, Handbook of lunar materials, United States, 1980.

[15] C. Cross, F.L. John, C. George, A Comparison of the Apollo and Early Orion Environmental Control, Life Support and Active Thermal Control System's Driving Requirements and System Mass, SAE Int. J. Aerosp. 1(1), 2009, pp. 300-306.

[16] S. Mottaghi and H. Benaroya, Design of a Lunar Surface Structure. I: Design Configuration and Thermal Analysis, Journal of Aerospace Engineering, 28(1), 2015, pp. 04014052-1-12.

[17] B.S.Hemingway, R.A. Robie and W.H. Wilson, Specific heats of lunar soils, basalt, and breccias from the Apollo 14, 15, and 16 land-ing sites, between 90 and $350^{\circ} \mathrm{K}$, Lunar and Planetary Science Conference 1973, NASA Lunar and Planetary Institute, 1973, pp. $2481-2487$.

[18] M.G. Langseth, S.J. Keihm and K.P eters, Revised lunar heat-flow values, Proc., Lunar and Planetary Science, 1976, pp. $3143-3171$. 